\title{
Genetic variation of CXCR4 and risk of coronary artery disease: epidemiological study and functional validation of CRISPR/Cas9 system
}

\author{
Guo Runmin ${ }^{1}$, Jiang Jiamei ${ }^{1}$, Jing Zhiliang ${ }^{2}$, Chen Yonghua ${ }^{2}$, Shi Zhizhou ${ }^{3}$, Tao \\ Guizhou ${ }^{4}$ and Liu Shuguang ${ }^{5}$ \\ ${ }^{1}$ Department of Cardiology, Affiliated Hospital of Guangdong Medical University, Zhanjiang, Guangdong 524001, P.R. China \\ ${ }^{2}$ Department of Pathology, Affiliated Hospital of Guangdong Medical University, Zhanjiang, Guangdong 524001, P.R. China \\ ${ }^{3}$ Department of Endocrinology and Metabolism, Longgang District People's Hospital, Shenzhen 518172, China \\ ${ }^{4}$ The Third People's Hospital of Dalian, Dalian, Liaoning 116091, P.R. China \\ ${ }^{5}$ Department of Pathology, The Eighth Affiliated Hospital, Sun Yat-Sen University, Shenzhen, Guangdong 518033, P.R. China
}

Correspondence to: Liu Shuguang, email: liu_shuguang@aliyun.com

Keywords: coronary artery disease; variation; genetic; CXCR4

Received: June 23, 2017 Accepted: October 05, 2017 Epub: December 15, 2017 Published: March 06,2018

Copyright: Runmin et al. This is an open-access article distributed under the terms of the Creative Commons Attribution License 3.0 (CC BY 3.0), which permits unrestricted use, distribution, and reproduction in any medium, provided the original author and source are credited.

\section{ABSTRACT}

Cardiovascular diseases (CVDs) remain the leading cause of death worldwide, while coronary artery disease (CAD) account for a large part of CVDs. Vascular CXCR4 could limit atherosclerosis by maintaining arterial integrity. Here, we conducted a populationbased, case-control study to evaluate the associations of common genetic variation within the CXCR4 gene (rs2228014, rs117600832, rs2471859, and rs2322864) with CAD risk in a Chinese population. We found that CXCR4 rs2228014 was significantly associated with 1.29-fold increased risk of CAD (A vs G: OR $=1.29 ; 95 \%$ CI $=1.07-1.55$; $P=0.007)$. The subjects with genotype AA $(O R=1.98 ; 95 \% C I=1.03-3.81 ; P=0.041)$ and AG (OR $=1.27 ; 95 \% C I=1.02-1.58 ; P=0.030)$ have higher risk of CAD, compared with those with genotype GG. Furthermore, both in the CAD patients with diabetes and those without diabetes, rs2228014 was significantly associated with increased risk of CAD $(P<0.05)$. Additionally, we also validated the significant association for rs 2322864 ( $C$ vs T: $O R=1.20 ; 95 \%$ CI $=1.00-1.44 ; P=0.046$ ). Knockout of CXCR4 gene could significantly impair the capacity of cholesterol efflux $(P<0.01)$. These findings strongly suggest that CXCR4 polymorphisms might contribute to CAD susceptibility, and the exact biological mechanism awaits further research.

\section{INTRODUCTION}

Coronary artery disease (CAD), also known as ischemic heart disease (IHD) and coronary heart disease (CHD), was the leading cause of death globally [1]. Although CAD mortality has gradually declined over the last decades in western countries, it still causes about onethird of all deaths in people older than 35 years worldwide [2]. Although traditional risk factors, such as age, male gender, smoking, alcohol drinking, obesity, hypertension, hypercholesterolemia, and diabetes mellitus have been identified to contribute to the pathogenesis of CAD, genetic factor also accounted for $30 \% \sim 60 \%$ of the risk of CAD [3-6]. Genome-wide association studies (GWASs) have identified many susceptibility loci for CAD, although large part of genetic etiology of CAD could not be explained until now [7-10]. These also included the contribution of the famous Framingham Heart Study, which was established in 1948 by the US Public Health Service [11].

Recently, Doring et al [12] reported that vascular CXCR4 could limit atherosclerosis through maintaining arterial integrity, preserving endothelial barrier function. This means enhancing arterial CXCR4 might open novel therapeutic options in atherosclerosis. CXCR4deficiency favored a synthetic phenotype, the occurrence of macrophage-like SMCs in the lesions, and impaired cholesterol efflux [12]. The CXCL12/CXCR4 axis have 
been found to play a critical role in coronary artery development [13]. A nested case-control study found that increased CXCR4 level in peripheral CD34+ cells was associated with good coronary collateralization in patients with chronic total coronary occlusion [14]. Genetic variations of CXCR4 have been linked to susceptibility of many phenotypes, including HIV/SIV infection, multiple cancers, and so on [15-18]. In this study, we performed a candidate gene study of CAD using a tag single-nucleotide polymorphism (tagSNP) approach for interrogating common genetic variation within the CXCR4 gene in a Chinese population.

\section{RESULTS}

\section{Characteristics of study subjects}

The characteristics of the study participants were summarized in Table 1. We totally included 1,200 unrelated CAD patients and 1,200 geographical-matched healthy controls in this study. No significant differences were found between cases and controls for age, gender, hypertension, and alcohol status. However, significant associations were detected for smoking status, family history of CAD, diabetes status, body-mass index, TC, TG and HDL-C $(P<0.005)$. When included in a logistic regression model, smoking status, family history of CAD, diabetes status, TC, TG and HDL-C were determine as the risk predictors of $\mathrm{CAD}$.

\section{Genotype analyses}

Table 2 summarized the genotypic frequencies of the four tagSNPs of the CXCR4 gene (rs2228014, rs117600832, rs2471859, and rs2322864) in Chinese CAD patients and healthy controls. The distribution of all the four CXCR4 variants in the controls was compatible with HWE $(P>0.05)$. After adjusted for age, gender, smoking status, drinking status, diabetes, hypertension, smoking status, family history of CAD, body-mass index, TC, TG and HDL-C, SNP rs2228014 showed significant association with increased CAD risk (A vs G: OR = $1.29 ; 95 \% \mathrm{CI}=1.07-1.55 ; P=0.007)$. The subjects with genotype $\mathrm{AA}(\mathrm{OR}=1.98 ; 95 \% \mathrm{CI}=1.03-3.81 ; P=0.041)$ and $\mathrm{AG}(\mathrm{OR}=1.27 ; 95 \% \mathrm{CI}=1.02-1.58 ; P=0.030)$ have higher risk of $\mathrm{CAD}$, compared with those with genotype GG. For rs2322864, we also detected a significant association $(\mathrm{C}$ vs $\mathrm{T}$ : $\mathrm{OR}=1.20 ; 95 \% \mathrm{CI}=1.00-1.44$; $P=0.046)$. No significant association was detected for CXCR4 rs117600832 and rs2471859.

\section{Stratified analyses}

To further evaluate the potential effect modification of the diabetes status, stratified analyses were conducted for rs2228014 (Table 3). Both in the CAD patients with diabetes and those without diabetes, rs2228014 was significantly associated with increased risk of CAD, which confirmed the robustness of the findings.

\section{Cholesterol efflux evaluation}

Furthermore, we evaluated the effect of knockout of the CXCR4 gene on the lesional cholesterol efflux. As shown in Figure 1, cholesterol efflux capacity was significantly lower in the CXCR4 knockout group $(P<0.01)$.

\section{DISCUSSION}

The current study explored the associations between four genetic variants of the CXCR4 gene and risk of CAD in a population-based, case-control study. We found that CXCR4 rs2228014 was significantly associated with 1.29-fold increased risk of CAD. Furthermore, both in the CAD patients with diabetes and those without diabetes, rs2228014 was significantly associated with increased risk of CAD. We also validated the significant association for rs2322864 in CAD patients.

CXCR4 gene was located at 2q22.1. This gene encodes a CXC chemokine receptor specific for stromal cell-derived factor-1, while the encoded protein has 7 transmembrane regions and is located on the cell surface [19]. CXCR4 was first found to mediate CD4-independent infection by HIV-2 in 1996 [20]. Since, there is increasing evidence that abnormal expression and genetic variation of CXCR4 is involved in several pathological conditions, including immune diseases, viral infections, multiple cancers, and cardiovascular diseases [21-35]. Recently, vascular CXCR4 was identified to limits atherosclerosis by maintaining arterial integrity, and rs2322864, a SNP located within the CXCR4 locus, was detected to be associated with increased risk for CAD [12]. The mechanism referred that CXCL12/CXCR4 chemokine ligand/receptor axis promoted endothelial barrier function through VE-cadherin expression and the stabilization of junctional VE-cadherin complexes [12].

With this background, we evaluated the genetic variants of the CXCR4 gene with risk of CAD, which identified a significant association for rs2228014 and validated the significant association for rs 2322864 in CAD patients. Combinational polymorphisms of seven CXCL12-related genes, including rs2228014, were found to be protective against breast cancer in Taiwan first [36]. A meta-analysis including 3684 cancer patients and 5114 healthy controls participating in 11 studies also showed that rs2228014 polymorphism was associated with a significantly increased risk of cancer in homozygote model $(\mathrm{OR}=2.01,95 \% \mathrm{CI}: 1.22-3.33)$ and in recessive model (OR $=1.97,95 \%$ CI: 1.23-3.16) [37]. In current study, our results indicated that SNP rs2228014 showed significant association with increased CAD risk (A vs G: $\mathrm{OR}=1.28 ; 95 \% \mathrm{CI}=1.07-1.54 ; P=0.007)$. 
Table 1: Clinical demographic characteristics of CAD cases and controls

\begin{tabular}{|c|c|c|c|}
\hline Variables & Cases $(n=1200)$ & Controls $(n=1200)$ & $P$ value \\
\hline \multicolumn{4}{|l|}{ Age } \\
\hline$\geq 60$ & $564(47.0 \%)$ & $596(49.7 \%)$ & 0.191 \\
\hline$<60$ & $636(53.0 \%)$ & $604(50.3 \%)$ & \\
\hline \multicolumn{4}{|l|}{ Gender } \\
\hline Male & $877(73.1 \%)$ & $859(71.6 \%)$ & 0.411 \\
\hline female & $323(26.9 \%)$ & $341(28.4 \%)$ & \\
\hline \multicolumn{4}{|l|}{ Smoking status } \\
\hline Smokers & $422(35.2 \%)$ & $241(20.1 \%)$ & $P<0.001$ \\
\hline Non-Smokers & $778(64.8 \%)$ & $959(79.9 \%)$ & \\
\hline \multicolumn{4}{|l|}{ Alcohol status } \\
\hline drinkers & $269(22.4 \%)$ & $250(20.8 \%)$ & 0.346 \\
\hline Non-drinkers & $931(67.6 \%)$ & $950(79.2 \%)$ & \\
\hline \multicolumn{4}{|l|}{ Diabetes } \\
\hline Yes & $449(37.4 \%)$ & $97(8.1 \%)$ & $P<0.001$ \\
\hline No & $751(62.6 \%)$ & $1103(91.9 \%)$ & \\
\hline \multicolumn{4}{|l|}{ Hypertension } \\
\hline Yes & $412(34.3 \%)$ & $433(36.1 \%)$ & 0.369 \\
\hline No & $788(65.7 \%)$ & $767(63.9 \%)$ & \\
\hline \multicolumn{4}{|l|}{ Family history of CAD } \\
\hline Yes & $127(10.6 \%)$ & $302(25.2 \%)$ & $P<0.001$ \\
\hline No & $1073(89.4 \%)$ & $898(74.8 \%)$ & \\
\hline Body-mass index & $24.1 \pm 2.4$ & $23.9 \pm 2.2$ & 0.033 \\
\hline $\mathrm{TC}(\mathrm{mmol} / \mathrm{L})$ & $4.55 \pm 0.65$ & $4.09 \pm 0.55$ & $P<0.001$ \\
\hline $\mathrm{TG}(\mathrm{mmol} / \mathrm{L})$ & $1.68 \pm 0.19$ & $1.58 \pm 0.18$ & $P<0.001$ \\
\hline HDL-C (mmol/L) & $1.55 \pm 0.26$ & $1.44 \pm 0.24$ & $P<0.001$ \\
\hline
\end{tabular}

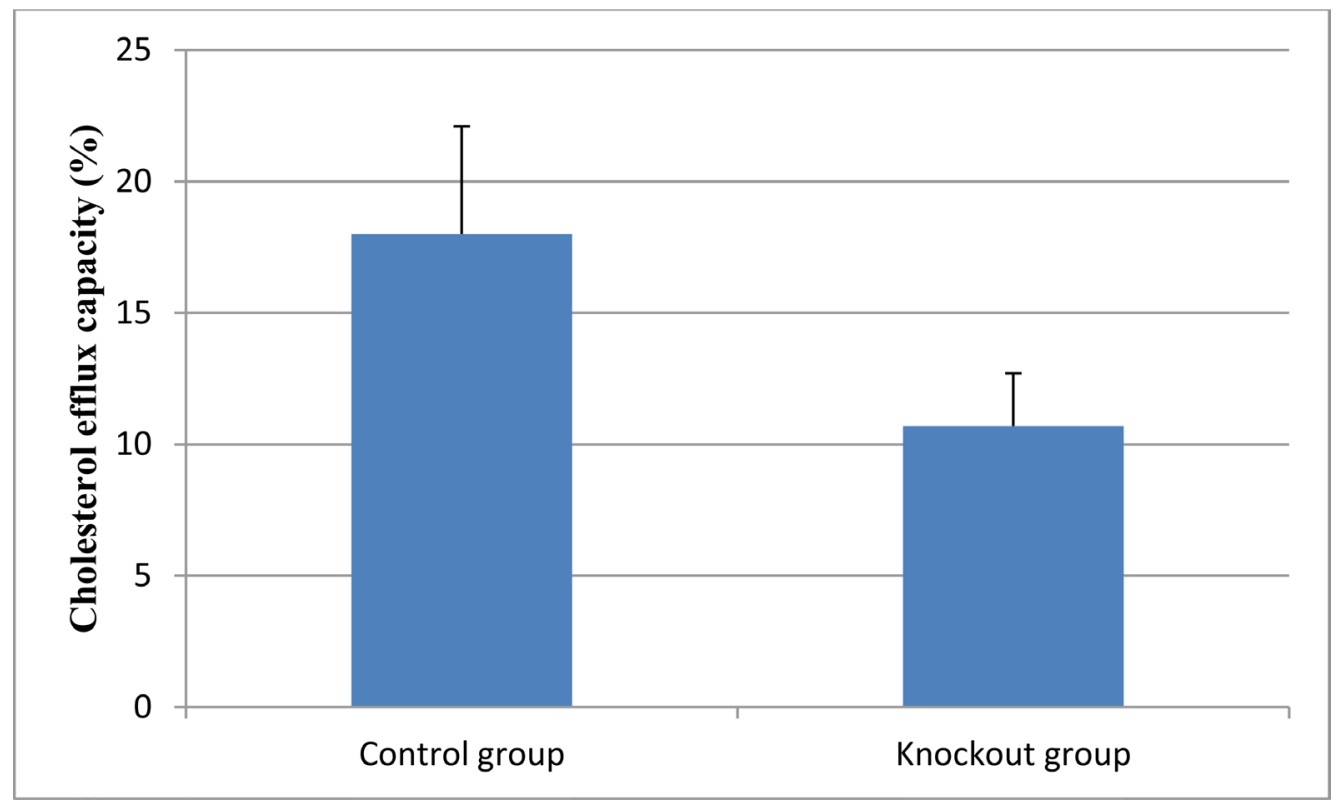

Figure 1: Cholesterol efflux capacity in the knockout and control group. Data are expressed as mean $\pm \mathrm{SD}$. 


\begin{tabular}{|c|c|c|c|c|}
\hline & CAD cases & Controls & OR $(95 \% \text { CIs })^{*}$ & $P$ value \\
\hline \multicolumn{5}{|l|}{ rs2228014 } \\
\hline GG & 844 & 896 & 1.00 (Reference) & \\
\hline AG & 331 & 290 & $1.27(1.02-1.58)$ & 0.030 \\
\hline $\mathrm{AA}$ & 25 & 14 & $1.98(1.03-3.81)$ & 0.041 \\
\hline A vs $G$ & & & $1.29(1.07-1.55)$ & 0.007 \\
\hline $\mathrm{AA}+\mathrm{AG}$ vs $\mathrm{GG}$ & $356 / 844$ & $304 / 896$ & $1.29(1.06-1.58)$ & 0.013 \\
\hline $\mathrm{AA}$ vs $\mathrm{AG}+\mathrm{GG}$ & $25 / 1175$ & $14 / 1186$ & $1.87(0.97-3.63)$ & 0.063 \\
\hline \multicolumn{5}{|l|}{ rs117600832 } \\
\hline GG & 1036 & 1045 & 1.00 (Reference) & \\
\hline CG & 151 & 145 & $1.09(0.71-1.67)$ & 0.691 \\
\hline $\mathrm{CC}$ & 13 & 10 & $1.35(0.55-3.30)$ & 0.511 \\
\hline C vs G & & & $1.11(0.82-1.49)$ & 0.492 \\
\hline $\mathrm{CC}+\mathrm{CG}$ vs $\mathrm{GG}$ & $164 / 1036$ & $155 / 1045$ & $1.11(0.77-1.59)$ & 0.570 \\
\hline $\mathrm{CC}$ vs $\mathrm{CG}+\mathrm{GG}$ & $13 / 1187$ & $10 / 1190$ & $1.35(0.55-3.35)$ & 0.510 \\
\hline \multicolumn{5}{|l|}{ rs2471859 } \\
\hline $\mathrm{AA}$ & 1049 & 1051 & 1.00 (Reference) & \\
\hline $\mathrm{AG}$ & 139 & 140 & $1.03(0.61-1.73)$ & 0.911 \\
\hline GG & 12 & 9 & $1.38(0.54-3.53)$ & 0.501 \\
\hline G vs A & & & $1.07(0.84-1.38)$ & 0.600 \\
\hline $\mathrm{GG}+\mathrm{AG}$ vs $\mathrm{AA}$ & $151 / 1049$ & $149 / 1051$ & $1.06(0.46-2.40)$ & 0.897 \\
\hline $\mathrm{GG}$ vs $\mathrm{AA}+\mathrm{AG}$ & $12 / 1188$ & 9/1191 & $1.39(0.54-3.54)$ & 0.490 \\
\hline \multicolumn{5}{|l|}{ rs2322864 } \\
\hline TT & 789 & 830 & 1.00 (Reference) & \\
\hline CT & 376 & 341 & $1.21(0.99-1.48)$ & 0.061 \\
\hline $\mathrm{CC}$ & 35 & 29 & $1.31(0.80-2.15)$ & 0.288 \\
\hline $\mathrm{C}$ vs T & & & $1.20(1.00-1.44)$ & 0.046 \\
\hline $\mathrm{CC}+\mathrm{CT}$ vs TT & $411 / 789$ & $370 / 830$ & $1.22(1.01-1.47)$ & 0.040 \\
\hline $\mathrm{CC}$ vs $\mathrm{CT}+\mathrm{TT}$ & $35 / 1165$ & 29/1171 & $1.30(0.78-2.16)$ & 0.312 \\
\hline
\end{tabular}

* Adjusted for age, gender, smoking status, drinking status, diabetes, hypertension, smoking status, family history of CAD, body-mass index, TC, TG and HDL-C.

This study also has several strength. First, the genetic background of cases and controls was well matched. To avoid false-positive associations caused by differences in age, gender and other covariates, we selected cases and controls that are well matched for age and gender, and ensured that the associations remained significant after adjustment for potential confounding bias; Second, the sample size were adequate; Third, results of rs2228014 remained significant after Bonferroni correction for multiple comparisons $(0.007 * 4$ $=0.028$, Bonferroni-adjusted). Also, several limitations of our study should be considered. First, inherent selection bias for case-control study; second, lack of replication in an independent population; third, we didn't reach a Bonferroni-adjusted statistical significance for rs2322864, although our sample size was moderate for a common variant; fourth, some other confounding factors may potentially mediate the effect of selected polymorphisms on CAD risk such as physical activity, diet habit, family history of other cardiovascular diseases and so on. However, these limitations do not detract from the main conclusions.

In conclusion, our study provided evidence that CXCR4 rs2228014 and rs2322864 were significantly associated with increased risk of CAD. The replications of our studies in other populations as well as further systematic investigations are needed to clarify the molecular mechanisms underlying CXCR4 regulation. 


\begin{tabular}{|c|c|c|c|c|}
\hline & CAD cases & Controls & OR $\left(95 \%\right.$ CIs) ${ }^{*}$ & $P$ value \\
\hline \multicolumn{5}{|c|}{ CAD with diabetes } \\
\hline GG & 315 & 896 & 1.00 (Reference) & \\
\hline $\mathrm{AG}$ & 124 & 290 & $1.27(0.96-1.68)$ & 0.095 \\
\hline AA & 10 & 14 & $2.12(0.97-4.65)$ & 0.061 \\
\hline A vs $G$ & & & $1.31(1.03-1.66)$ & 0.026 \\
\hline $\mathrm{AA}+\mathrm{AG}$ vs $\mathrm{GG}$ & $134 / 315$ & $304 / 896$ & $1.30(1.00-1.69)$ & 0.049 \\
\hline $\mathrm{AA}$ vs $\mathrm{AG}+\mathrm{GG}$ & $10 / 339$ & $14 / 1186$ & $2.60(1.18-5.72)$ & 0.018 \\
\hline \multicolumn{5}{|c|}{ CAD without diabetes } \\
\hline GG & 529 & 896 & 1.00 (Reference) & \\
\hline $\mathrm{AG}$ & 207 & 290 & $1.27(0.99-1.62)$ & 0.055 \\
\hline AA & 15 & 14 & $1.89(0.91-3.93)$ & 0.088 \\
\hline A vs $G$ & & & $1.29(1.05-1.59)$ & 0.017 \\
\hline $\mathrm{AA}+\mathrm{AG}$ vs $\mathrm{GG}$ & $222 / 529$ & $304 / 896$ & $1.29(1.02-1.62)$ & 0.032 \\
\hline $\mathrm{AA}$ vs $\mathrm{AG}+\mathrm{GG}$ & $15 / 736$ & $14 / 1186$ & $1.79(0.85-3.77)$ & 0.122 \\
\hline
\end{tabular}

* Adjusted for age, gender, smoking status, drinking status, hypertension, smoking status, family history of CAD, body-mass index, TC, TG and HDL-C.

\section{MATERIALS AND METHODS}

\section{Study subjects}

In current study, we included a total of 1,200 unrelated patients with CAD which were recruited between before Oct 2016. The diagnosis of CAD was certified by coronary angiography performed via a quantitative coronary angiographic system. CAD was defined as luminal narrowing of more than $50 \%$ in one or more main coronary arteries. Control subjects comprised 1,200 healthy subjects from the same geographical area who were undergoing a routine check-up. All the participants were Chinese-Han population. A face to face interview and a review of the medical records were implemented to collect the demographic and clinical characteristics data. After the interview, five milliliter peripheral venous blood was collected in tubes containing disodium-EDTA as an anticoagulant and then stored at $-80^{\circ} \mathrm{C}$ until genomic DNA extraction. All the subjects included in this case-control study were given an informed consent and also the study protocol.

\section{Variable definition}

Diabetes was diagnosed with at least one of the following criteria: 1) a random venous plasma glucose concentration $\geq 11.1 \mathrm{mmol} / 1 ; 2$ ) a fasting plasma glucose concentration $\geq 7.0 \mathrm{mmol} / \mathrm{l} ; 3$ ) two hour plasma glucose concentration $\geq 11.1 \mathrm{mmol} / 1$ (two hours afer $75 \mathrm{~g}$ anhydrous glucose in an oral glucose tolerance test). A diagnosis of hypertension was based on the presence of elevated systolic ( $\geq 140 \mathrm{mmHg}$ ) and/or diastolic $(\geq 90$ $\mathrm{mmHg}$ ) blood pressure, or current use of antihypertensive medications. Smoking was defined as the non-casual current or ever inhalation of the smoke of burning tobacco encased in cigarettes, pipes, and cigars. While alcohol status was defined as frequent alcohol consumption.

\section{TagSNP selection, DNA extraction, and genotyping}

The TagSNPs were selected using the pairwise LD function of the SNAP (https://www.broadinstitute.org/ $\mathrm{mpg} / \mathrm{snap} /$ ) web server [38]. These resulted three tagSNPs of the CXCR4 gene were selected, including rs2228014, rs 117600832, and rs2471859. We also including the SNP rs2322864, which was located in the flanking region of the CXCR4 gene and detected previously [12]. Genomic DNA used for SNPs genotyping was extracted from peripheral blood lymphocytes using a DNA extraction kit (TianGen, Beijing, China). The genotyping was conducted using SEQUENOM Mass-ARRAY system. For quality control, genotyping was performed without knowledge of the case or control status. One hundred random-selected samples were tested in duplicate, and the reproducibility was $100 \%$.

\section{CRISPR/Cas9-mediated knockout of the CXCR4 gene}

The guide RNAs were designed to recognize the CXCR4 Gene using the CRISPR Design Tool (http:// crispr.mit.edu/). The guide RNA with the highest score was selected, and cloned into the PGL3 plasmid. Precise genome editing in mice was performed using the 3-component CRISRP-Cas9 system, while the knockout of CXCR4 gene was confirmed by sequencing. Then we analyzed the effect of CRISPR/Cas9-mediated knockout of the CXCR4 
gene on the lesional cholesterol efflux. Efflux is given as the percentage of counts recovered from the medium in relation to the total counts present on the plate. All efflux experiments were performed in duplicate for each sample.

\section{Statistical analysis}

The statistical analysis on the characteristics of the subjects was performed with Student's $t$-test for the continuous variables, while Pearson x2 test was used for the categorical variables. The genotypes were tested for Hardy-Weinberg equilibrium (HWE) using Fisher's exact test in controls. The logistic regression models were performed to calculate the odds ratios (ORs) and 95\% confidence intervals (CIs) and adjust the potential confounding factors by including these factors in the regression models. Statistical analysis was performed on SPSS v. 19.0 software (SPSS, Chicago, IL). A $P$ value $<0.05$ was considered statistically significant.

\section{CONFLICTS OF INTEREST}

The authors declare that they have no conflicts of interest.

\section{FUNDING}

This study was supported by grants from the Guangdong Natural Science Foundation (No. 2015A030310359, 2016A030313678, 2016A030310359) and grants from the National Natural Science Foundation of China (No. 81670348 and 81703762).

\section{REFERENCES}

1. Lozano R, Naghavi M, Foreman K, Lim S, Shibuya K, Aboyans V, Abraham J, Adair T, Aggarwal R, Ahn SY, Alvarado M, Anderson HR, Anderson LM, et al. Global and regional mortality from 235 causes of death for 20 age groups in 1990 and 2010: a systematic analysis for the Global Burden of Disease Study 2010. Lancet. 2012; 380:2095-2128.

2. Sanchis-Gomar F, Perez-Quilis C, Leischik R, Lucia A. Epidemiology of coronary heart disease and acute coronary syndrome. Ann Transl Med. 2016; 4:256.

3. Marenberg ME, Risch N, Berkman LF, Floderus B, de Faire U. Genetic susceptibility to death from coronary heart disease in a study of twins. N Engl J Med. 1994; 330:1041-1046.

4. Qasim A, Matthews L, Qu L, Movva R, Parcham-Azad K, DerOhannessian S, Ferguson J, Li M, Rader D, Reilly M. Association of genome wide loci for cad with distribution of coronary disease. J Am Coll Cardiol. 2010; 55:A124.

5. Trégouët DA, König IR, Erdmann J, Munteanu A, Braund PS, Hall AS, Grosshennig A, Linsel-Nitschke P, Perret C,
DeSuremain M, Meitinger T, Wright BJ, Preuss M, et al. Genome-wide haplotype association study identifies the SLC22A3-LPAL2-LPA gene cluster as a risk locus for coronary artery disease. Nat Genet. 2009; 41:283-285.

6. Kathiresan S, Voight BF, Purcell S, Musunuru K, Ardissino D, Mannucci PM, Anand S, Engert JC, Samani NJ, Schunkert H, Erdmann J, Reilly MP, Rader DJ, et al. Genome-wide association of early-onset myocardial infarction with single nucleotide polymorphisms and copy number variants. Nat Genet. 2009; 41:334-341.

7. Nikpay M, Goel A, Won HH, Hall LM, Willenborg C, Kanoni S, Saleheen D, Kyriakou T, Nelson CP, Hopewell JC, Webb TR, Zeng L, Dehghan A, et al. A comprehensive 1,000 Genomes-based genome-wide association meta-analysis of coronary artery disease. Nat Genet. 2015; 47:1121-1130.

8. Lu X, Wang L, Chen S, He L, Yang X, Shi Y, Cheng J, Zhang L, Gu CC, Huang J, Wu T, Ma Y, Li J, et al. Genomewide association study in Han Chinese identifies four new susceptibility loci for coronary artery disease. Nat Genet. 2012; 44:890-894.

9. Hartiala JA, Tang WH, Wang Z, Crow AL, Stewart AF, Roberts R, McPherson R, Erdmann J, Willenborg C, Hazen $\mathrm{SL}$, Allayee H. Genome-wide association study and targeted metabolomics identifies sex-specific association of CPS1 with coronary artery disease. Nat Commun. 2016; 7:10558.

10. Tang W, Schwienbacher C, Lopez LM, Ben-Shlomo Y, Oudot-Mellakh T, Johnson AD, Samani NJ, Basu S, Gogele M, Davies G, Lowe GD, Tregouet DA, Tan A, et al. Genetic associations for activated partial thromboplastin time and prothrombin time, their gene expression profiles, and risk of coronary artery disease. Am J Hum Genet. 2012; 91:152-162.

11. Chen G, Levy D. Contributions of the framingham heart study to the epidemiology of coronary ceart disease. JAMA Cardiol. 2016; 1:825-830.

12. Doring Y, Noels H, van der Vorst EPC, Neideck C, Egea V, Drechsler M, Mandl M, Pawig LB, Jansen Y, Schroder K, Bidzhekov K, Megens RTA, Theelen W, et al. Vascular CXCR4 limits atherosclerosis by maintaining arterial integrity: evidence from mouse and human studies. Circulation. 2017; 136:388-403.

13. Ivins S, Chappell J, Vernay B, Suntharalingham J, Martineau A, Mohun TJ, Scambler PJ. The CXCL12/CXCR4 axis plays a critical role in coronary artery development. Dev Cell. 2015; 33:455-468.

14. Yang C, Zhu W, Han X, Ma A, Bai L, Xu F. Association of CXCR4 expression with coronary collateralization in patients with chronic total coronary occlusion: A nested case-control study. Int J Cardiol. 2017; 228:501-506.

15. Matsusaka S, Cao S, Hanna DL, Sunakawa Y, Ueno M, Mizunuma N, Zhang W, Yang D, Ning Y, Stintzing S, Sebio A, Stremitzer S, Yamauchi S, et al. CXCR4 polymorphism predicts progression-free survival in metastatic colorectal cancer patients treated with first-line bevacizumab-based chemotherapy. Pharmacogenomics J. 2016; 17:543-550. 
16. Okuyama Kishima M, Brajao de Oliveira K, Ariza CB, de Oliveira CE, Losi Guembarovski R, Banin Hirata BK, de Almeida FC, Vitiello GA, Trugilo KP, Guembarovski AF, Jorge Sobrinho W, Campos CZ, Watanabe MA. Genetic polymorphism and expression of CXCR4 in breast cancer. Anal Cell Pathol (Amst). 2015; 2015:289510.

17. Oda JM, de Oliveira KB, Guembarovski RL, de Lima KW, da Silva do Amaral Herrera AC, Guembarovski AL, Sobrinho WJ, Derossi DR, Watanabe MA. TGF-beta polymorphism and its expression correlated with CXCR4 expression in human breast cancer. Mol Biol Rep. 2012; 39:10131-10137.

18. Puissant B, Abbal M, Blancher A. Polymorphism of human and primate RANTES, CX3CR1, CCR2 and CXCR4 genes with regard to HIV/SIV infection. Immunogenetics. 2003; 55:275-283.

19. D’Apuzzo M, Rolink A, Loetscher M, Hoxie JA, ClarkLewis I, Melchers F, Baggiolini M, Moser B. The chemokine SDF-1, stromal cell-derived factor 1, attracts early stage B cell precursors via the chemokine receptor CXCR4. Eur J Immunol. 1997; 27:1788-1793.

20. Endres MJ, Clapham PR, Marsh M, Ahuja M, Turner JD, McKnight A, Thomas JF, Stoebenau-Haggarty B, Choe S, Vance PJ, Wells TN, Power CA, Sutterwala SS, et al. CD4-independent infection by HIV-2 is mediated by fusin/ CXCR4. Cell. 1996; 87:745-756.

21. Pozzobon T, Goldoni G, Viola A, Molon B. CXCR4 signaling in health and disease. Immunol Lett. 2016; 177:6-15.

22. Zhong J, Rajagopalan S. Dipeptidyl peptidase-4 regulation of SDF-1/CXCR4 axis: implications for cardiovascular disease. Front Immunol. 2015; 6:477.

23. Chatterjee S, Behnam Azad B, Nimmagadda S. The intricate role of CXCR4 in cancer. Adv Cancer Res. 2014; 124:31-82.

24. Arnolds KL, Spencer JV. CXCR4: a virus's best friend? Infect Genet Evol. 2014; 25:146-156.

25. Yadav VN, Zamler D, Baker GJ, Kadiyala P, ErdreichEpstein A, DeCarvalho AC, Mikkelsen T, Castro MG, Lowenstein PR. CXCR4 increases in-vivo glioma perivascular invasion, and reduces radiation induced apoptosis: A genetic knockdown study. Oncotarget. 2016; 7:83701-83719. https://doi.org/10.18632/oncotarget.13295.

26. Taromi S, Kayser G, Catusse J, von Elverfeldt D, Reichardt W, Braun F, Weber WA, Zeiser R, Burger M. CXCR4 antagonists suppress small cell lung cancer progression. Oncotarget. 2016; 7:85185-85195. https://doi.org/10.18632/ oncotarget.13238.

27. Wu W, Cao J, Ji Z, Wang J, Jiang T, Ding H. Co-expression of Lgr5 and CXCR4 characterizes cancer stem-like cells of colorectal cancer. Oncotarget. 2016; 7:81144-81155. https://doi.org/10.18632/oncotarget.13214.

28. Krook MA, Hawkins AG, Patel RM, Lucas DR, Van Noord $\mathrm{R}$, Chugh R, Lawlor ER. A bivalent promoter contributes to stress-induced plasticity of CXCR4 in Ewing sarcoma. Oncotarget. 2016; 7:61775-61788. https://doi.org/10.18632/ oncotarget. 11240 .
29. Saint-Georges S, Quettier M, Bouyaba M, Le Coquil S, Lauriente V, Guittat L, Levy V, Ajchenbaum-Cymbalista F, Varin-Blank N, Le Roy C, Ledoux D. Protein kinase D-dependent CXCR4 down-regulation upon BCR triggering is linked to lymphadenopathy in chronic lymphocytic leukaemia. Oncotarget. 2016; 7:41031-41046. https://doi. org/10.18632/oncotarget.9031.

30. Circelli L, Sciammarella C, Guadagno E, Tafuto S, del Basso de Caro M, Botti G, Pezzullo L, Aria M, Ramundo V, Tatangelo F, Losito NS, Ierano C, D'Alterio C, et al. CXCR4/CXCL12/CXCR7 axis is functional in neuroendocrine tumors and signals on mTOR. Oncotarget. 2016; 7:18865-18875. https://doi.org/10.18632/ oncotarget.7738.

31. Azad BB, Chatterjee S, Lesniak WG, Lisok A, Pullambhatla M, Bhujwalla ZM, Pomper MG, Nimmagadda S. A fully human CXCR4 antibody demonstrates diagnostic utility and therapeutic efficacy in solid tumor xenografts. Oncotarget. 2016; 7:12344-12358. https://doi.org/10.18632/ oncotarget.7111.

32. Buske C, Kirchhoff F, Munch J. EPI-X4, a novel endogenous antagonist of CXCR4. Oncotarget. 2015; 6:35137-35138. https://doi.org/10.18632/oncotarget.6037.

33. Inaguma $\mathrm{S}$, Riku M, Ito $\mathrm{H}$, Tsunoda $\mathrm{T}$, Ikeda $\mathrm{H}$, Kasai K. GLI1 orchestrates CXCR4/CXCR7 signaling to enhance migration and metastasis of breast cancer cells. Oncotarget. 2015; 6:33648-33657. https://doi.org/10.18632/ oncotarget.5203.

34. Zhao H, Guo L, Zhao J, Weng H, Zhao B. CXCR4 overexpression and survival in cancer: a system review and meta-analysis. Oncotarget. 2015; 6:5022-5040. https://doi. org/10.18632/oncotarget.3217.

35. Ablett MP, O'Brien CS, Sims AH, Farnie G, Clarke RB. A differential role for CXCR4 in the regulation of normal versus malignant breast stem cell activity. Oncotarget. 2014; 5:599-612. https://doi.org/10.18632/oncotarget.1169.

36. Lin GT, Tseng HF, Yang CH, Hou MF, Chuang LY, Tai HT, Tai MH, Cheng YH, Wen CH, Liu CS, Huang CJ, Wang CL, Chang HW. Combinational polymorphisms of seven CXCL12-related genes are protective against breast cancer in Taiwan. OMICS. 2009; 13:165-172.

37. Wu Y, Zhang C, Xu W, Zhang J, Zheng Y, Lu Z, Liu D, Jiang $\mathrm{K}$. CXC motif chemokine receptor 4 gene polymorphism and cancer risk. Medicine (Baltimore). 2016; 95:e5317.

38. Johnson AD, Handsaker RE, Pulit SL, Nizzari MM, O’Donnell CJ, de Bakker PI. SNAP: a web-based tool for identification and annotation of proxy SNPs using HapMap. Bioinformatics. 2008; 24:2938-2939. 